\title{
Strategies for Educators of Bilingual Students: A Critical Review of Literature
}

\author{
Chris Sclafani \\ Hofstra University, Hempstead, New York, USA \\ E-mails: csclafani1@pride.hofstra.edu
}

Received: $25-02-2017$

Accepted: $30-03-2017$

Published: $30-04-2017$

doi:10.7575/aiac.ijels.v.5n.2p.1

URL: http://dx.doi.org/10.7575/aiac.ijels.v.5n.2p.1

\begin{abstract}
The education of bilingual students is a rather popular topic among educators in today's schools. Frequently, articles and research focus upon a singular phenomenon or strategy in this field. This literature review is aimed at providing teachers of students of all grade levels and ages with a guide containing prevalent theories and ideas related to providing high quality instruction to students with bilingual backgrounds. Educational practices such as translanguaging and the integration of biliteracy can assist students in using their native tongues along with the dominant language of their given settings. Additionally, the usage of cooperative groups and language buddies not only creates a sense of "fitting in" for new bilinguals, but also recognizes the ideology that young learners will learn the social aspects of a new language prior to learning the more academic and formalized version of speaking. Both new and experienced teachers would benefit from training that relates to these culturally responsive teaching strategies. There are also sections within this piece that promote the usage of community and parent outreach methods that aim to improve the school experience for all involved parties. The overarching goal of this literature review is providing teachers with a variety of literature connected to relevant theory and useful strategies that could potentially assist them in better understanding bilingual students, as well as enhance their overall knowledge base of this subject matter.
\end{abstract}

Keywords: Bilingual Education, Biliteracy, Translanguaging, Teaching Strategies, School Community

\section{Introduction}

The recent developments in the field of bilingual education can be utilized to create a scenario that is both inclusive and supportive of all students in a school community. While the concept of bilingual scholars is nothing new, the manner in which we most proficiently foster positive learning experiences for these scholars has been immensely refined over the past few years. This is an ever-growing and vast field of study that can reap voluminous positive benefits. "Bilingual classroom contexts are hugely varied, with multiple models and structures existing in different education systems across the world" (Creese \& Blackledge, 2010, p. 103). The ultimate goal for this compilation of research is to examine common themes and practices that can be implemented to most wholly provide for the needs of students possessing bilingualism.

The American population is gradually diversifying as time goes on, and it is time for some procedural constructs to be put into place for bilingual students. While it is common for some type of process to be employed when a new bilingual student arrives, often it is either lacking one area (parent contact, teacher preparation, etc.), and support will frequently not continue for that student over a long period of time. While time restrictions and bureaucracy can be an obstacle to the implementation of the proposed changes, it is clear that there is sufficient research to support these ideas. The goal is to find the optimal learning conditions for bilingual students, based on the latest information and data that is available. There might be a large array of strategies presented, but this wide-ranging approach is a necessity since they can be altered or adopted to fit a particular educational situation.

The culture of schools must first shift from an existing model that emphasizes "English first", or simply "English proficiency". Unfortunately, many schools promote ignoring or minimizing the roles of any other languages that the student is able to use outside of English. "Schools having the opportunity to create models of multi-literacy and transculturalism often opt to develop practices with an exclusive linguistic code: English" (Rodriguez-Valls, 2009, p. 132). Such singular and short-sighted ideologies are being disproven or thought to be outdated amidst the more modern data. An attempt is being made to overturn the "tyranny of the majority" or the "tyranny of the masses" (Mill, 1859) whereas that which is commonplace tends to become the norm, regardless of whether it is considered to be best practice. In this case, that type of thinking is perhaps harmful. In places like Massachusetts, there were laws being upheld less than a decade ago that completely disallowed children to learn in languages outside of English. This shows the depths at which these "English only" ideas have promulgated. When referring to the plethora of educational labels put forth relating to bilingual students, Reyes (2012) notes, "None of these terms acknowledge bilingualism/biliteracy as part of cultural capital that children bring to school and as an asset that could be and should be used as a resource for learning" (p. 308). It seems as if students who possess linguistic skills in more than one language are treated as if they are different in ways that are not placed in positions of high esteem within typical educational infrastructures. 
Hornberger and Link (2011) turn to President Obama's candid outlook on the matter which is supportive of a change in traditional thinking as well, and he makes the following case for change, "Instead of worrying about if immigrants will learn English - they'll learn English - you need to make sure your child can speak Spanish. You should be thinking about, how can your child become bilingual?" (p. 261). Arguments such as this must play largely into the decision making process in the creation of accepting environments for both bilingual and monolingual students alike. According to August and Shanahan (2006), "87\% of dual-language learners in the United States are enrolled in English-only classrooms that neglect or ignore their native linguistic competencies to the detriment of their academic achievement" (p. 6). This wide overview of the national data serves to further intensify the need for a change in practice occur. A resounding majority of students are being negatively affected by our current state of affairs relating to the treatment of students who possess multiple languages. Such a position is supported by Garcia and Li Wei (2013) when they discuss the imposition of monolingual standards in a society that is mostly multilingual (p. 52).

\section{Translanguaging}

Translanguaging is the central axis upon which much of the current progressive theory rests. It is a vital part of the shift from the aforementioned "English-first" or "English-only" mentality. Alternatively, this is an approach that allows students to have a larger influence over the language acquisition and usage process. "Translanguaging does not view the languages of bilinguals as separate linguistics systems. The term stresses the flexible and meaningful actions through which bilinguals select features in their linguistic repertoire in order to communicate appropriately" (Garcia \& Velasco, 2014). Some of the key words here are "flexible" and "select". Students use both their native tongues and the dominant language of school to variant degrees. There is more free choice given to students who are permitted to openly translanguage. Unlike rigid systems that value a singular language choice, or adhere to a rigid 50/50 split, the above quote is propagating the notion that user is in control of these linguistic percentages, and may shift them according to the situation at hand. "It is also important to consider that most bilingual education programs in the United States have as their goal 'English proficiency for students"” (Dworin, Moll, \& Saez, 2001, p. 445). By its very existence, translanguaging goes against many previously accepted forms of instruction. "The norms and standards that come with monolingual orientation have served as a benchmark for language assessment and social stratification for a long time. The translingual orientation disturbs these arrangements" (Canagarajah, 2013, p.14). This is vital factor to be considered as a structure is put in place to best support students who are bilingual. Translanguaging presents widespread and varied chances for students to find their collective ways linguistically in pathways that they have the power to dictate.

\subsection{Biliteracy}

Biliteracy is a goal that finds itself alongside translanguaging in importance. It is a critical concept for teachers to comprehend, and for students to work towards. "Biliteracy is a term used to describe children's literate competencies in two languages, to whatever degree, developed either simultaneously or successively" (Dworin, 1998, p.3). A key element that should be noted is the fact that like translanguaging, there are also variant degrees of biliteracy. It is not something that has certain point of qualification where someone is suddenly considered biliterate. Dual or multiple language literacy must be a non-negotiable acceptance for teachers wishing to accommodate bilingual students. Reyes (2012) further clarifies this point by recognizing, “' At the individual level, biliteracy development is represented as occurring on a dynamic continuum that is infinite rather than having polar opposite endpoints. Important to this model is that literacy is viewed as a social practice, thus highlighting the social context in which biliteracy is nested (p. 309). Reyes adds to Dworin's theory by adding the factor of a social context for the literacy experiences, which thereby meshes well with the oral practices of translanguaging. Also, the notion of degrees finds itself more clearly defined as a placement on a continuum that is ever shifting and not terminal in nature. Biliterate students are free to express themselves in their language of choice based upon their background knowledge, social situation, and/or specified task.

\subsection{English as a Contact Language}

There is potential for situations in which a majority of a given class or grade level are bilingual, yet they possess a very wide variety of differing languages. Hence, language buddies would be more difficult to enact, and communication efforts can become more complicated. Moreover, even informal social communication in the home language is more difficult to achieve due to this variance. First, one must keep in mind the worthy, long-term, research-proven goal of allowing translanguaging and promoting biliteracy. "Part of our efforts as educators must be to ensure that we keep translanguaging from becoming just another strategy to deal with a problem (Garcia \& Li Wei, 20130, p. 95). Languages are not the problem here, they are actually the answer. Canagarajah (2013) discusses a creative ideology that allows students to maintain their complex and wide-ranging linguistic identities, and then places English as a "contact language" (p.72).

In essence, teachers must wholly commit to letting go of preconceived notions of "proper English" and traditional thought, for all of this to come together in a serviceable fashion. "Meaning is an inter-subjective accomplishment. As interlocutors adopt negotiation strategies to align diverse semiotic resources, they construct a hybrid form that meshes different languages for situated meaning" (Canagarajah, 2013, p. 72). This would allow each student to own their own version of English that is specific to them and their backgrounds. These contact versions of English would vary by user, topic matter, other participants, and need. Since the central common language in a polyglot grouping would be English, students can generate meaningful language experiences that push and sometimes step outside of more formally held boundaries in order for effective communication to occur. 


\section{Teacher Preparation}

For any major shift in thinking and/or action to occur, the proper tools must be given to those are asked to help enact such changes. Teacher training is something that must not be overlooked. "Research-based professional development is essential for districts and teachers across the nation that face the challenge of providing a quality education for increasingly diverse student populations" (Karabenik \& Noda, 2004, p.55). Educators must be provided with assistance in generating opportunities to create the proper set of circumstances to efficiently foster translanguaging and biliteracy. "School policy may need to be developed to that provides teachers with culturally responsive professional development" (Orosco \& O'Conor, 2013). This idea of "culturally responsive instruction" appears to be initially championed by K.H. Au (1993), who defined the term as "Instruction consistent with the values of students' own cultures and aimed at improving academic learning" (p. 13). It is not difficult to see how such an attitude would lead to a learning space that is both welcoming and accepting of bilingual scholars. Additionally, other members of the class would be learning valuable character education lessons that are modeled by both the teacher and the members of the class. Faculties could more readily galvanize in making positive strides towards more modern ways of thinking about children and language. "The tide is slowly moving away from separating languages in the classroom to the use of two or more languages in the same lesson" (Baker, Jones \& Lewis, 2013, p.3).

Field experience is considered valuable and it is required for anyone entering the teaching field. The thought that one needs to practice or actively partake in something that they will someday be implementing is extremely common. The preparation of teachers of bilingual students could follow the same formula. In one particular development model, future instructor candidates do the same tasks as their future students. "Many candidates have commented on the practical nature of the strategies ad approaches exemplified in the following. '...actually doing reciprocal teaching, literature circles, and book clubs gave us a complete overview of what to expect and what kinds of things to prepare..."” (Oliva \& Sarmiento, 2006, p. 80). This kind of experiential learning is suitable for teacher training workshops, grade level meeting times, and faculty gatherings. The above methods can be introduced slowly throughout the course of the year with specific goals that can build with each trial.

\section{Parent Training}

The inclusion of parents into any type of large scale supportive model for students is a true necessity. The involvement of the home unit has been proven over decades to improve academic success rates, and this holds true for both bilingual and monolingual pupils (Simich-Dudgeon, 1986, p.1-2). However, there are some complexities that can potentially show up when dealing with diverse populations involving cultural norms or specific approaches that reap greater benefits than more traditionally held monolingual education models. When researching parent educational attitudes across various cultures, researcher Yan Guo (2010) found that there are conflicting perspectives of teachers and bilingual parents relating to their particular roles within the education of children (p. 85). While studying the prevalent, dictating thought processes of each particular culture is not necessary (or feasible), it is simply important to understand that these different opinions about the educational role of schools and families exist, and that they impact the various roles of the home in academia. Teachers must be proactive in bridging these gaps, or at the very least, be aware of their existence. "Explain certain school procedures and expectations that may be unique to American schools (such as an emphasis on cooperative learning, portfolio assessment, parent volunteerism and so on)" (Shore, 1998, p. 2). Teachers also should be sure that there is clarity about the acceptance of translanguaging and biliterate behaviors. "Many immigrant families are anxious for their children to 'fit in' and to become part of mainstream American society. While this is important for their child's well-being, it is often at the expense of their native language" (Nettles, 2006, p. 75). Families' concerns will often be assuaged by open communication in whatever language suits the child at that time. By eliminating or decreasing misconceptions, the teacher is able to form a partnership with parents more readily.

There will be times when the parents of students will feel threatened or put off by the language barrier that they perceive between the dominant language of the school and its instructors, and their main language. Additionally, parents must deal with school calendars and correspondences that will all likely be printed in English, along with conferences/school events that are likely to follow a similar pattern. Educational institutions must do their part in eliminating possible aspects of this problem that fall within their control. "Schools can encourage more linguisticminority involvement through teacher training and the enhancement of the school environment to make it more appealing the diverse families" (García \& Frede, 2010, p. 109). Shore (1998) notes that when translation is possible, it should be done for the aforementioned academic materials. This would allow for a more seamless relationship between the school and the family (p. 2). Parents would benefit greatly from knowing exactly what is going on, and may feel more included, as the idea of translation lends itself to a more inclusive manner of thought.

The work with parents should not stop at physical documents, but should be pushed further to allow more comfort when parents who do not have full command of English come in for a conference or a school event. A person who is in charge of linking the home and school communities is present in a great deal of research. Such a person would have a large role in connecting the "two worlds" of home and school. "An essential component of the parent involvement effort is the bilingual community liaison" (Simich-Dudgeon, 1986, p. 4). After researching the impact of dominant language imposition upon Asian families in Canadian English-speaking schools, Guo (2010) more clearly defines the role for Simich-Dudgeon's liaison. "An intermediary is a bilingual staff member or parent liaison who is sensitive to community needs and my act as an ambassador for relations between the home, community, and school" (p.125). This 
person could serve as the "face of the school" for bilingual parents, acting as someone who is aware of their needs, and likewise has an awareness of how to interweave these needs, concerns, and hopes into the greater vision of the school and its staff. A "go-to" person such as this would quickly become invaluable to those who are in contact with him/her. California has seen this position as a necessity and has built it into their Family Biliteracy Program requirements. They are not the only area to confirm the research above with job vacancies that must be filled. Many openings can be found for language intermediaries of varying degrees across the United States and Canada. As there is a greater general awareness of our diversity, it is possible that this type of vocation will grow in both importance and numbers in the years to come.

\section{Direct Strategies}

Students will be impacted the most in a school setting by the atmosphere and approaches within their classrooms. There are well-founded practices that teachers must be brave enough to begin employing during the school day, although many of them fly in the face of the antiquated view that honors "filling children with English" under the belief that "reading is a neutral act". "Common instructional routines may need to be adjusted" (August \& Francis, 2006, p.2). There are some courses of action that are dependent upon the age of the bilingual child. Others are more universal in their application.

\subsection{Language Buddies}

One strategy that appeared to be useful regardless of student age is the idea of a language buddy, or child translator. Shore (1998) recommends that the language buddies could be constant for younger students and perhaps rotate in the case of a child who is old enough to change classes (p. 2). This progressive approach appears simplistic, but bears obvious positive implications. Thoughts and ideas could be translated or "brokered" to ensure that sufficient learning and support of learning is taking place.

The selection of a language buddy for a new student is not an arbitrary decision, nor is an instructor bound by their first choice. Also, assumptions that the selected student will know how to mediate both their responsibility to the class work and their new-found role as an intermediary must be removed. Schools must find ways to aid students in navigating these roles. Research has indicated that training students who are appear as candidates for potential language buddies could be an answer. "The training should focus on the specific expectations of the buddies as well as of their partners. Also, recruit the help of the ESL teacher, who can show the buddies or tutors some simple teaching techniques and strategies" (Hamayan \& Perlman, 1990, p. 7). The added support from a master teacher in this area will create a more beneficial experience for all involved. Additionally, after doing extensive case studies with bilingual students, (Mayes, 2003) concluded that teachers must foster a language buddy program, and that when properly conducted, would lead to proven positive social and academic progress (p. 150).

Although the language buddy could alleviate burdens from the teacher, there are certain items that need to be addressed or monitored on a regular basis. There appears to be no specific or research-defined time period for which a buddy partnership should continue. This must be predicated on those who are directly involved. "The duration of the formal partnership between a buddy or a tutor and a language minority student varies." (Hamayan \& Perlman, 1990, p. 8). The instructor is then in charge of making crucial decisions about when to terminate this system and allow the students to try things for themselves. Hamayan and Perlman (1990) also warn the teachers to be careful in their respective treatment of the student translator or language broker (p.8). Facilitators of this process must also be mindful of the fact that one goal of this program is to "Foster a sense of belonging" (Shore, 1998, p.1). All pertinent speech should be directed at the proper students. It was found that instructors often singled out the trained buddy to relay information along instead of speaking directly to the appropriate parties. Failure to do so could result in feelings of alienation or inadequacy. One final piece relates again to the translator. Orellana (2009) suggests that students become representation for those around them, often engaging acts like positioning or advocacy that lack the neutrality that is assumed by most about translation. The term "language brokering" emerges to more comprehensively describe the actions that are included in this interchange. Language is a medium of negotiation for these children (p. 25). Both students find greater levels of empowerment through this type of paired activity, even though word-for-word translation is not a possible or realistic expectation.

\subsection{Using Events to Celebrate Different Ethnic Backgrounds}

The usage of the cultural celebration has grown over time in schools, and while on the surface, it appears to be just another school event, it allows students access to the traditions and customs of others. "Highlight the cultural backgrounds of your students" (Ariza, 2006, p. 153). It is also an opportunity for bilingual students to find a further foothold with classmates and it places them, and potentially the families in the spotlight for positive reasons. Mayes (2003) indicated that by "honoring the home and culture", both bilingual students and their parents viewed the school with higher levels of confidence after realizing that their values and background were not looked down upon by school staff and/or attendees (p. 150). As mentioned earlier, the need for parental support is key. This is one step that can be taken to continue to build that bond.

The classroom and school community also benefit greatly from events that promote understanding and giving added thought to diversity. Unspoken barriers between cultures that are often a result of misunderstandings, or a simple lack of knowledge begin to break down. "These ideas are a great way to enhance self-esteem, and the students will be 
noticeably prouder of their heritage and family if the teacher celebrates their background" (Ariza, 2006, p. 153). Thus, that which is wrongfully marked, might begin find greater levels of tolerance. A key word in the above quote is "celebrates", as it goes far beyond the idea of basic recognitions or understandings.

\subsection{Identity Projects}

A helpful project for some classrooms is a "cultural identity project". Students are able to look deeply into their lives and ethnicities. Students will be given a chance to put together some type of presentation or paper that talks about their roots, and their linguistic leanings. "Have the students create family history histories, interview older family members or neighbors (in either language) by audio, video, or writing" (Ariza, 2006, p. 153). Not only does research of this nature support the individual, but it also serves a valuable purpose in understanding where others come from, and the many traditions and norms that exist in the lives of their classmates. Also, in Ariza's version of this work, it is noteworthy to see that the choice of which language may be used is up to the student involved. Oliva and Sarmiento (2006) observed the long-term effects of these kinds of family-history projects, and they have described them as "transformative" (p. 81).

\subsection{Cooperative Learning Groups}

Cooperative learning is yet another student-based ideology that allows the teacher to formulate infrastructures for the group to utilize in meaningful ways, either for their own purposes or for those prescribed by the instructor. As social language development outpaces academic language development, cooperative learning provides an opportunity to streamline both of these speech versions in a singular experience. "Students to a large extent learn to speak by speaking. The single greatest advantage of cooperative learning over traditional classroom organization for the acquisition of language is the amount of language output allowed per student" (Kagan \& Spencer, 1995, p. 3). These ideas are consistent with many current educational approaches today such as "reading and writing workshop", where ownership is given to the students, and the belief is that learning is best when actual, genuine, practice time is allotted. There will be time for translanguaging and discussion of biliteracy-related events.

Literature Circles are a very common form of cooperative learning in modern classrooms. Their focal point is to get students to talk in a responsible way about text using various roles that rotate at delineated points during the overall reading experience.

One of the reasons literature circles have coalesced so strongly and generated so much excitement among teachers is that they make heterogenenous classrooms work. You can have a very diverse class of kids, with widely mixed 'ability' levels, assorted cultural and ethnic identities, even lots of mainstreamed special education children, and still have an exciting, challenging, orderly, and caring atmosphere for everyone. In other words, literature circles - along with reading and writing workshops - are a key structure for detracking schools, which is one of the greatest unsolved issues of educational justice in our country. (Daniels, 2002, p. 36)

These groupings also serve to surpass ethnic cultural boundaries that might be perceived as holding students back in their participation. Carrison and Ernst-Slavit (2005) studied this phenomenon in action. Students were sometimes working in a team setting for the first time in their school careers. Teachers must address this by being very clear about the task and the expectations. Sharing and discussion are the centerpiece of the activity, thus any preconceptions about talking in class or sharing opinions must give way to the circle roles (p. 94). Bilingual students can be allowed to position themselves according to their own levels of comfort. They can become more involved if they feel confident, or sit back at times when they are more uncertain. Also, the roles that are part of this activity provide bilingual students with chances to process text and create a variety of products in a low-risk atmosphere. An overview of direct strategies is presented in Table 1.

\section{Inside the Culturally Responsive Classroom}

The classroom itself can be a key scaffold for bilingual students. If set up and aligned properly to the needs of the students, room construction and the items contained within that room become powerful allies to educators and students alike. Garcia and Li Wei (2013) recommend that word walls be placed in clear sight to allow students to have repetitive exposure to vocabulary words (p. 128). The inclusion of these word walls will also permit the students to more readily encode these chosen vocabulary words. In some cases, there will be those that wish to experiment with the usage of words from the wall, perhaps assimilating them into their everyday speech. The daily exposure that accompanies word walls generates more confidence in the meaning and contextual understanding of the words contained in them.

One must take full advantage of the current technology to assist bilinguals. Much importance can be placed on "the availability and production of technologically enhanced media, including iPads and computers" (Garcia \& Li Wei, 2013, p.127). Websites like Myon.com and Reading A-Z offer books in a wide variety of languages including English/Spanish and English/French companion texts that would allow for monolinguals to read the same text as their bilingual counterparts. Biliteracy could occur in a very pure sense, as choices are made by the students themselves about what portions of the e-book they wish to read in a given language. Responses can be structured in a very similar manner, as students are presented with options regarding the language(s) they want to utilize. 
Table 1. An Overview of Direct Strategies

\begin{tabular}{|c|c|c|}
\hline Strategy & Basics & Potential Benefits \\
\hline $\begin{array}{l}\text { Language } \\
\text { Buddies }\end{array}$ & $\begin{array}{l}\text { A carefully selected student is assigned by the } \\
\text { teacher to assist with language translation for a } \\
\text { new bilingual student. The students work closely } \\
\text { with one another. The translator must speak the } \\
\text { same language(s) as the bilingual student. }\end{array}$ & $\begin{array}{l}\text { - New bilingual students are able to communicate } \\
\text { with the teacher through translation. } \\
\text { - The new student can interact socially with their } \\
\text { language buddy. }\end{array}$ \\
\hline $\begin{array}{l}\text { Diversity- } \\
\text { Based } \\
\text { Events }\end{array}$ & $\begin{array}{l}\text { Students and their families are invited to the } \\
\text { school for a celebration of the various cultures } \\
\text { and ethnicities within the school community. }\end{array}$ & $\begin{array}{l}\text { - Families are able to discuss their customs with } \\
\text { others. } \\
\text { - Bilingual families might have an opportunity to } \\
\text { meet other families with similar backgrounds. }\end{array}$ \\
\hline $\begin{array}{l}\text { Identity } \\
\text { Projects }\end{array}$ & $\begin{array}{l}\text { The students look into their ethnic backgrounds } \\
\text { and do research on their family's history and } \\
\text { languages. They can use the Internet and/or } \\
\text { interviews with members of their family } \\
\text { members to obtain this information. }\end{array}$ & $\begin{array}{l}\text { - The class honors the differences between the } \\
\text { various cultures of the students. } \\
\text { - Bilingual students can share their unique family } \\
\text { stories with their peers. }\end{array}$ \\
\hline $\begin{array}{l}\text { Cooperative } \\
\text { Learning } \\
\text { Groups }\end{array}$ & $\begin{array}{l}\text { Small groups are organized by the teacher } \\
\text { allowing bilingual students to work with their } \\
\text { classmates. Often, these groups consist of mixed } \\
\text { ability levels. }\end{array}$ & $\begin{array}{l}\text { - Bilingual students can experiment with social } \\
\text { language, which often develops before } \\
\text { academic language. } \\
\text { - Student participation can vary on individual } \\
\text { comfort level. }\end{array}$ \\
\hline
\end{tabular}

The classroom library can also be a point of interest when thinking about supporting students from all backgrounds.

Make multiculturalism real. Make it a part of your everyday experiences for all of your students. One the easiest way to do this is with children's literature. Using these books throughout the year, you can share with all of your students' stories, biographies, poetry, and nonfiction that give them exposure to worlds outside their own. (Nettles, 2006, p. 79)

Students will be able to form personal connections to these reading experiences, and also come to a greater understanding of the way that others might live. This cultural awareness is invaluable in a classroom that gears itself towards biliteracy.

\section{Conclusion}

Educating a child is a holistic experience that must be inclusive of goals from the home, the school, and from that particular student. Instructors must step out of roles that might be given to them under teacher-centered pedagogical models and adapt to suit the multiple needs of all students in the classroom. "The teacher then becomes the facilitator, generating opportunities for language use, and not seeing herself as the linguistic authority, but as another language learner" (Garcia and Li Wei, 2013, p.75). Teachers engage in the processes with or by the students, but do not become the sole person responsibility for imparting knowledge about language and culture. Students need to be given chances to do this for themselves and their classmates. This is evident in the previously referenced literature by Shore (1998) and Hamayan and Perlman (1991) when they refer to language buddies as a scaffold that should be in place for a new bilingual student. Cooperative learning groups such as Daniels' (2002) literature circles also allow bilingual students to work closely with their classmates and interact socially within the constructs of an academic setting. This social development piece is augmented by the implementation of cultural celebration events that honor the diversity of students from all ethnicities, as well as by cultural identity projects allowing bilingual students to share their family histories in a welcoming and accepting environment.

In order to create this environment, teachers will need ongoing training regarding the most effective means for creating culturally responsive classrooms. Aside from the obvious benefits that students receive from well-trained faculty, training sessions of this nature can create the notion that school administrators expect to see bilingual students treated with the various approaches that the teachers have learned. Additionally, when training is done frequently, it is far easier to bring new teachers into the fold, thus perpetuating and expanding a successful situation for the bilingual members of the school community.

The recognition of parents as important partners in the education of their children is another item that should be in the forefront of those who educate bilinguals. Bilingual parents should not feel as if they are outsiders in any way. This is why translation (when possible) should be readily available during important gatherings such as conferences or open school nights. Translation could also be used for documents that are sent home from the school. When these services 
appear to be limited, the school could employ a liaison who serves as the link between the school and bilingual parents. Informed parents are able to make more enlightened decisions with respect to the education of their children.

Teachers should also ensure that they take advantage of opportunities that capitalize on the linguistic and cultural knowledge that bilingual students possess, and weave them into instruction. Garcia and Velasco (2014) discuss how translanguaging allows students to access and speak their native language as well as the dominant language of the given area on a sliding scale that works best for their particular level of understanding. This process can be enhanced by the employment of a biliteracy approach that gives students the freedom to work with reading and writing in a nearly identical fashion to translanguaging. When given a larger pool of linguistic resources that extends to their language of origin, it appears that students can focus more upon an actual task that is assigned to them, as opposed to primarily becoming concerned with finding the proper words in the dominant language to complete that task.

While there is a great deal of concise and clear research in the field of educating bilinguals, there are many opportunities for further research. The area of cooperative learning is one that is frequently defined in broad terms. More data about specifically when to change up preset cooperative groups to allow children to work with other classmates would be a helpful addition. Research about the specific number of children that is optimal for these groups would also be an area for further study. Language buddies is a method that would benefit from further studies as well. It is usually accepted that the student and the language buddy will begin to dissolve their formal "buddy" relationship over the course of time. However, a study that reviews both teacher and student accounts about the nuances of how and when these arrangements were successfully dissolved could assist educators moving forward. Perhaps some patterns would emerge. Finally, there are a wide array of books and articles devoted to the pedagogical approaches and theories involving teaching bilinguals, yet there are few that solely address assisting the children on an emotional level. Generally, bilingual children have been uprooted from their birth nation or region to move to new and different surroundings. Further research about how to best mentally support the child through a time of potentially high stress would be an important addition.

No longer should we see a new bilingual student in the room, sitting in the back looking confused. An end can be placed to the hesitation that some students have before admitting that they speak a less dominant language in their household. All languages can live and breathe in an environment that understands the culture behind them, and praises their usage. The power is in our hands to make these changes. We will never know the differences that can be made until we strive for what we know is best each and every day.

\section{References}

Ariza, E. (2006). Not for ESOL teachers: What every classroom teacher needs to know about the linguistically, culturally, and ethnically diverse student. Boston, MA: Pearson/Allyn and Bacon.

Au, K. H. (1993). Literacy instruction in multicultural settings. Fort Worth, TX: Harcourt Brace Jovanovich College Publishers.

August, D. \& Shanahan, T. (2006). Synthesis: Instruction and professional development. In D. August \& T. Shanahan (Eds.), Developing literacy in second-language learners. Mahwah, NJ: Lawrence Erlbaum Associates.

August, D. \& Francis, D. (2006). Literacy for Diverse Learners. Mahwah, NJ: Lawrence Erlbaum Associates.

Baker, C., Jones, B., \& Lewis, G. (2013). Translanguaging: Origins and development from school to street and beyond. Educational Research and Evaluation.

Blackledge, A. \& Creese, A. (2010). Translanguaging in the bilingual classroom: A pedagogy for learning and teaching? The Modern Language Journal, 94(10), 103-115.

Canagarajah, A. (2013). Translingual practice: Global Englishes and cosmopolitan relations. Milton Park, Abingdon, Oxon: Routledge.

Carrison, C. \& Ernst-Slavit G. (2005). From silence to a whisper to active participation: Using literature circles with ELL students. Reading Horizons, 46(2), 93-113.

Daniels, H. (2002). Literature circles voice and choice in book clubs and reading groups (2nd ed.). Portland, Me.: Stenhouse.

Dworin, J. (1998). Biliteracy development: The appropriation of literacy in English and Spanish by second and third grade students. The University of Arizona.

García, E. \& Frede, E. (2010). Developing the Research Agenda for Young English Language Learners. NYC: Teachers College Press.

Garcia, O. \& Li Wei. (2013) Translanguaging Language, Bilingualism and Education. New York: Palgrave Macmillan.

Garcia, O. \& Velasco, P. (2014) Translanguaging and the writing of bilingual learners. Bilingual Research Journal: The Journal of the National Association for Bilingual Education, 37(1), 6-23. 
Guo, Y. (2006). Why didn't they show up? Rethinking ESL parent involvement in k-12 education. TESL Canada Journal, 24(1), 80-95.

Guo, Y. (2010). Meetings without dialogue: A study of ESL parent-teacher interactions at secondary school parents' nights. School Community Journal, 20(1), 121-140.

Hamayan, E. \& Perlman, R. (1990). Helping language minority students after they exit from bilingual/ESL programs: A handbook for teachers. Washington, D.C.: National Clearinghouse for Bilingual Education.

Hornberger, N. \& Link, H. (2012). Translanguaging and transnational literacies in multilingual classrooms. A biliteracy lens. International Journal of Bilingual Education and Bilingualism, 15(3), 261-278.

Karabenik, S.A. \& Clemens Noda, P.A. (2004). Professional development implications of teachers' beliefs and attitudes toward English Language Learners. Bilingual Research Journal, 28(1), 55-75.

Mayes, L. (2003). When ESL is not enough in identification, assessment and programming for ESL learners with special/additional needs: Five case studies, BCTF Research, 141-161.

Mill, J.S. (1859). On Liberty. London: Parker.

Moll, L., Saez, R., \& Dworin, J. (2001). Exploring biliteracy: Two student case examples of writing as a social practice. Elementary School Journal, 101(4), 435-449.

Nettles, D. H. (2006). Comprehensive literacy instruction in today's classrooms: The whole, the parts, and the heart. New York: Pearson.

Olivos, E. \& Sarmiento, L. (2006). Is there room for biliteracy? Issues in Teacher Education, 15(1), 69-84.

Orellana, M.F. (2009) Translating childhoods. Immigrant youth, language, and culture. New Brunswick, Rutgers University Press.

Orosco, M. J. \& O’Connor, R. (2013). Culturally responsive instruction for English language learners with learning disabilities. Journal of Learning Disabilities, 47(6), 515-531.

Reyes, I. (2012) Biliteracy among children and youth. Reading Research Quarterly, 47(3), 307-327.

Rodriguez-Valls, F. (2009). Cooperative biliteracy: Parents, students, and teachers read to transform. English Teaching: Practice and Critique, 8(2), 114-136.

Shore, K. (1998). Success for ESL students. Scholastic Instructor. New York: Scholastic Publications 1-3.

Simich-Dudgeon, C. (1986). A Parent involvement model for use with limited English proficient high school students: The vocationally oriented bilingual curriculum, English-Lao. ERIC Digest. Washington, D.C.: Trinity College 1-9. 